\title{
CAPítTLLO 9
}

\section{LINGUIISTICA FORENSE EM}

DIACRONIA

\section{APONTAMENTOS TERMINOMÉTRICOS DA VARIAÇÃO DEFLORAMENTO/ESTUPRO NO SERGIPE OITOCENTISTA}

Sandro Marcio Drumond Alves Marengo

Natália Larizza Sanches de Souza Mariana Augusta da Conceição Fonseca

\section{CONSIDERAÇ̃̃ES INICIAIS}

A Linguística Forense é um campo de atuação da Linguística que se centra no estudo da linguagem da lei e dos tribunais, da polícia e prisões, ou seja, no estudo da linguagem usada nos mais diversos tipos de interações dentro do contexto jurídico. Apesar de as bases da linguística forense estarem assentadas e voltadas em sua grande maioria para uma visão sincrônica da linguagem jurídica, nossas pesquisas regridem temporalmente e, inseridos em uma visão diacrônico-sistemática, nos interessa não só uma descrição da estrutura e dos usos da linguagem de especialidade jurídica, mas também os movimentos de variação e mudança que encerram essa linguagem, seja do ponto de vista intrassistêmico - com vínculo direto com a socioterminologia sincrônica (FAULSTICH, 2002) e diacrônica (MARENGO; CAMBRAIA, 2016, MARENGO, 2016, 2017, 2018b) seja do extrassistêmico, com relação às conformações das tradições discursivas (SIMÕES; KEWITZ, 2010) e com a história da cultura escrita (MARENGO, 2018a) desse tipo particular de objeto.

Caldas-Coulthard (2014) aponta que a Linguística Forense pode ser dividida em três grandes áreas de investigação: 
a) A linguagem como prova/evidência, representado pelo trabalho de perícia que realiza estudos e exames de evidência ou prova linguística, de ordem fonética, léxico-gramatical ou pragmática, para serem arrolados como prova/evidência nos mais variados tipos de conflitos jurídicos.

b) Interação em contextos forenses, que reúne pesquisas centradas na linguagem oral das interações jurídicas produzidas em fóruns, delegacias de polícia e outros contextos legais.

c) Linguagem e Direito, em que o principal foco de estudos é a linguagem escrita de documentos jurídicos, fonte de dados que o linguista forense utiliza para analisar a linguagem jurídica e suas características particulares.

No caso particular do nosso estudo, como as fontes primárias de século XIX são unicamente escritas, estamos circunscritos à área de "Linguagem e Direito". No entanto, como nosso objetivo é mensurar a circulação dos termos jurídicos defloramentolestupro dentro de processos legais, que são tradições discursivas escritas conformadas de interações legais representadas por diferentes tipologias textuais, também nos inserimos em "Interação em contextos forenses". Assim, já que nossa interação é de cunho escrito, estamos ampliando a definição de Caldas-Coulthard (2014), que restringe esse âmbito à oralidade.

O caráter terminométrico ${ }^{1}$ do estudo em tela parte da nossa proposta maior de mapeamento, em tempo real de longa duração, da mudança léxico-semântica do par estupro/defloramento nos processos judiciais oitocentistas e novecentistas do Estado de Sergipe, levando em consideração seus usos por agentes especializados da interação (aqueles que têm formação jurídica, como juízes, advogados, promotores de justiça, por exemplo), por agentes semiespecializados (que não têm formação jurídica, mas convivem com grande frequência com os conceitos especializados, como os escrivães) e por agentes não-especializados (aqueles que não têm formação jurídica e que trazem conformações conceituais dos termos a partir do empirismo, como a ofendida e as testemunhas no processo). Dessa

\footnotetext{
Entendemos por terminometria o procedimento metodológico pelo qual se tratam estatisticamente os termos de um corpus para que seja mensurada a trajetória dos conceitos a eles atribuídos.
} 
forma, veremos como o conjunto termo-conceito circula, dentro de uma esfera de especialidade, de acordo com os interagentes.

Como estamos tratando de um fenômeno cuja base se assenta na sociolinguística, será essa a nossa abordagem. Acreditamos, portanto, que as nuances da mudança linguística no nível léxico-semântico serão condicionadas pelos usuários da língua, não só pelo seu grau de pertença a um grupo de especialidade, mas também pelo seu uso moldado por variáveis de gênero, etnia, idade, educação e profissão. Como a interação legal ocorre em ambientes sociais especializados, ricos em combinações dessas e de outras variáveis, ratificamos a grande importância da sociolinguística para a Linguística Forense.

\section{OS CAMINHOS PARA UMA SOCIOTERMINOLOGIA DIACRÔNICA}

Pensar um caminho para a Terminologia de viés diacrônico é algo bastante recente. A primeira vez que se tratou dessa possibilidade foi no Colóquio Terminologia Diacrônica, ocorrido na Bélgica, no ano de 1988. Segundo Hanse (1989, p.22), no seu discurso de abertura, o evento teve três eixos: (1) história da ciência dos termos; (2) história dos vocabulários; e (3) Terminologia diacrônica e suas relações com a sociedade ${ }^{2}$. Até aquele momento, não se concebia validade científica aos estudos terminológicos em caráter diacrônico. Foi a partir desse colóquio que houve uma relativa mudança desse panorama. Como podemos verificar na fala de um dos congressistas:

Se concebermos a Terminologia como esta parte da epistemologia que estuda a relação entre o pensamento científico e linguagem científica, será assumido que a linguagem não pode ser concebida como diacrônica. A essência da ciência e da indústria é a sua dimensão de tempo (o famoso PROGRESSO) e pode-se estudar a linguagem da ciência através do estudo de seu desenvolvimento. [...] Este exemplo demonstra que um termo científico deve ser estudado pelo terminólogo em diacronia ${ }^{3}$. (BAUDET, 1989, p.64-65).

2 “Ce coloque porte sur l'histoire de la terminologie. On a prévu trois perspective historiques (histoire de la Science des termes, histoire de vocabulaires, terminologie diachronique et société) avant déboucher judicieusement sur une prospective". (HANSE, 1989, p.22).

3 Tradução nossa. No original, "Si l'on conçoit la terminologie comme cette partie de l'épistémologie qui étudie la rapport entre pensée scientifique et langage scientifique, on admettra que la terminologie ne peut être conçue que comme diachronique. L'essence même de la science et de l'industrie est leur caratère temporel (le fameux PROGRÈS) et on ne peut étudier les langues de la science qu'en étudiant leur développement. [...] Cet exemple montre bien qu'un terme scientifique doit être étudié par le terminologue en diachronique." (BAUDET, 1989, p.64-65) 
A conferência proferida por Baudet explicita, de modo claro e com argumentos científicos sustentáveis, usando como exemplo a terminologia do campo siderúrgico, que a Terminologia pode e deve ser estudada em diacronia. Desse momento em diante, temos o que podemos nomear de o despontar da Terminologia diacrônica. Barros (2004), em sua periodização historiográfica dos estudos terminológicos, propõe que o estágio atual de investigações e estudos no campo terminológico começou na década de 1990. Na visão da autora, a partir daquele momento, os pressupostos teóricos e metodológicos das ciências passaram por revisões gerais em todo o mundo. $\mathrm{O}$ "[...] questionamento a respeito do modelo normalizador da Terminologia conduzem à Socioterminologia, à proposta de "libertação das amarras" da TGT e à proposta de um novo paradigma, expresso pela Teoria Comunicativa da Terminologia (TCT), proposta por Maria Teresa Cabré.” (BARROS, 2004, p.36).

A Socioterminologia é a disciplina que tem por objetivo principal a identificação e a categorização das aparentes variantes linguísticas dos termos em contextos distintos, que se regulam por diferentes tipos de situação de uso da língua ${ }^{4}$. Já a TCT, de acordo com Cabré (1999), articula-se levando em conta o valor dos aspectos comunicativos das linguagens especializadas em detrimento dos propósitos normalizadores, bem como na compreensão de que as unidades terminológicas estão inseridas na linguagem natural e na gramática das línguas. O que é mais evidente, tanto na TCT quanto na Socioterminologia, e de extrema importância para trabalhos em (Socio)Terminologia diacrônica, é que essas teorias acolhem o princípio da variação em toda sua dimensionalidade, pois preconizam que a unidade lexical pode assumir uma função especializada ou não, admitindo, dessa feita, que o conteúdo do termo não é fixo.

É nesse ínterim que a Terminologia diacrônica intensifica seu espaço, dez anos depois da realização do Colóquio de Bruxelas. Dessa vez, na Espanha, na cidade de Barcelona, celebrou-se o Colóquio A história das linguagens ibero-românicas de especialidade: séculos XII-XIX. De acordo com Souza (2007, p. 53), o principal objetivo desse evento foi “[...] revisitar a concepção tradicional da Terminologia: apropriação e rupturas de epistemologias que norteavam a Terminografia do final da Idade Moderna, a partir de uma pesquisa diacrônica, tomando como essencial os conceitos e suas relações." O colóquio, além de ocupar o espaço recente das pesquisas terminológicas em diacronia, também levantou pontos importantes como a influência da globalização nas perspectivas de estudos da área.

4 Posição também compartilhada por Cabré (1999) e Barros (2004). 
A ideia de que o processo de globalização é o ponto norteador da Terminologia no século XXI é ponto pacífico no nosso estudo, uma vez que sabemos que as rápidas inovações tecnológicas, principalmente a popularização e acessibilidade à rede mundial de computadores, produziram uma revolução nos processos de intercâmbio das informações:

\begin{abstract}
Razões de outra ordem também motivam o interesse pelo componente lexical especializado dos idiomas. Entre elas, destaca-se o processo de globalização que, incrementando as transações comerciais entre as nações, propiciou o surgimento dos atuais blocos econômicos, bem como de uma série de intercâmbios que ultrapassaram o âmbito comercial, expandindo-se para o mundo científico, tecnológico e cultural. [...] Nesse momento de globalização, também surge uma grande preocupação com a tradução dessas línguas de especialidade. Além disso, a inserção múltipla da tecnologia e de outras ciências faz com que os usuários se preocupem mais em saber utilizar os termos específicos. (KRIEGER; FINATTO, 2004, p.27).
\end{abstract}

Com base nas afirmações das autoras supracitadas, podemos ratificar a posição de Anjos (2003, p.35), ao dizer que “[...] o grande desafio da Terminologia, que nasceu justamente de uma necessidade advinda da Revolução Industrial, é lidar com o Século da Informação e com uma rápida e constante evolução científica e técnica".

\title{
2 VARIAC̦ÃO, MUDANÇA E SOCIOTERMINOLOGIA
}

Tratar de variação, principalmente de mudança, na Terminologia é algo relativamente novo. No Brasil, foi em 1989, um ano após a realização do Congresso de Bruxelas, que "[...] surgiram as primeiras ideias de que, no discurso, o termo apresentava variação" (FAULSTICH, 2001, p. 20). A partir de 1990, os estudos de variação terminológica ganham mais reforço, pois outros estudiosos da área também passam a assumir a variação como fenômeno ocorrente nas linguagens de especialidade, refutando, então, os postulados de Wüster, que afirmava que as variações terminológicas poderiam (e deveriam) ser eliminadas por meio da normalização dos termos.

Cabré (1993, p. 157) vai de encontro às proposições de perspectiva tradicional wüsteriana, ao afirmar que "[...] toda linguagem de especialidade, na medida em que é um subconjunto da língua comum, compartilha de suas mesmas características; trata-se, então, de um código unitário que permite variações”.5. Endossando

5 Tradução nossa. No original, “[...] todo lenguaje de especialidad, en la medida en que es un subconjunto del general, participa de sus mismas características; se trata, pues, de un código unitario que permite variaciones." 
esse posicionamento, Faulstich (1998) desmistifica ainda mais a sistematização terminológica de Wüster ao afirmar que os termos de uma linguagem de especialidade são entidades variantes que se manifestam nos planos vertical, horizontal e temporal. Tanto Cabré quanto Faulstich adotam a orientação funcional das linguagens de especialidade, uma vez que admitem o texto e o discurso especializados como elementos centrais no desenvolvimento dos estudos terminológicos.

\begin{abstract}
Apesar da persistência desse conceito, há alguns anos se começou a questionar certas afirmações sobre o unitarismo e se começou a desenvolver uma proposta de terminologia concentrada na análise textual dentro de um marco da comunicação especializada e viés cultural próprios das ciências da linguagem. Consequentemente, se começou a descrever o seu caráter variacionista. (CABRÉ, 1999, p. 166) ${ }^{6}$.
\end{abstract}

Nesse contexto, ratificando as palavras da autora supracitada, Faulstich afirma que a polifuncionalidade da unidade lexical é capaz de produzir mais de um registro ou mais de um conceito para o mesmo termo, uma vez que será esse o espaço em que as variantes serão "[...] resultantes dos diferentes usos que a comunidade, em sua diversidade social, linguística e geográfica, faz do termo" (FAULSTICH, 2001, p.22). Ao tratar dos diferentes usos de uma comunidade, é necessário ressaltar que estamos usando o conceito de comunidade de práticas. Chamamos atenção para esse fato, pois ele também se constituiu como determinante para a escolha do nosso alinhamento com uma metodologia e abordagem de estudos sociolinguísticos de terceira onda propostos por Eckert. Nesse sentido, nos esclarece Eckert (2004) que

\footnotetext{
O termo comunidade de fala tende a implicar uma coalescência de residência e atividade diária, mas os falantes se movem dentro e fora da comunidade. Desde que nos concentramos em uma comunidade como uma unidade estática que, em última análise, se opõe à mudança, é essencial visualizar comunidades como criações sociais. [...] A comunidade de prática é um agregado de pessoas que se reúnem em torno de algum empreendimento. Unidos por esse empreendimento comum, as pessoas vêm para desenvolver e compartilhar maneiras de fazer as coisas, maneiras de falar, crenças, valores - em suma, práticas - como uma função de seu engajamento conjunto em uma atividade. Simultaneamente, as relações sociais se formam em torno das atividades e as atividades se formam em torno dos relacionamentos. Tipos particulares de conhecimento, experiência, e formas de participação se tornam parte de identidades
}

6 Tradução nossa. No original, "Malgrat la persistència d'aquesta concepció, des de fa pocs anys s'han començat a posar em qüestió determinades afirmacions unitaristes i s'há començat a desenvolupar una proposta de la terminologia concentrada en la serva anàlisi en un marc textual dins de la comunicació especialitzada i amb el biaix cultural propi de les ciències del llenguatge. En conseqüència, s'ha començat a descriure el seu caràter variat." 
individuais e lugares na comunidade. (ECKERT, 2004, p. 34-35)7.

Assim sendo, afirmamos que os termos defloramento/estupro pertencem ao rol da linguagem de especialidade jurídica e são partilhados, dentro de um processo-crime, por diferentes comunidades de práticas: os agentes especializados da lei, os agentes semiespecializados da lei e os agentes não-especializados, como apontamos ao início do nosso texto. Essa delimitação é necessária porque, segundo Faulstich (2002, p. 66), “[...] é fundamental que o especialista em terminologia conheça o perfil do usuário, para que o repertório terminológico [...] se transforme num instrumento de trabalho e seja fonte de informação lexical e semântica das áreas específicas do conhecimento". Ademais, é importante afirmar que os conceitos que os termos portam são fruto de atividades cognitivas e interativas compartilhadas entre sujeitos. A conceptualização de mundo bem como o modelo mental que se cria a partir dele são, em grande parte, partilhadas entre os sujeitos, construindo-se, assim, a base do entendimento mútuo (KLEIBER, 1999).

Assim, notamos a importância dos sujeitos na comunicação especializada, uma vez que são eles que geram e usam os conceitos e sua materialização expressa no léxico de uma língua. Não se pode desprezar o fato de que tanto os sujeitos quanto suas manifestações linguísticas estão circunscritos à sociedade. Desse modo, a linguagem que usam, seja geral ou de especialidade, não só reflete as construções cognitivas individuais e partilhadas pela coletividade, mas também aponta para o modo como essa comunidade mapeia o mundo ao seu redor. Matoré (1953) nos afirma que

Na realidade, as palavras não exprimem as coisas, mas a consciência que os homens têm delas. Para a lexicologia, os fatos sociais têm, com efeito, o aspecto de coisas, mas das coisas vistas, sentidas, compreendidas pelos homens; nossa disciplina deverá então visar às realidades sociológicas das quais o vocabulário é a "tradução", ao mesmo tempo objetivamente, como realidades independentes do indivíduo, e subjetiva-

7 Tradução nossa. No original, "The term speech community tends to imply a coalescence of residence and daily activity, but speakers move around both inside and outside the community. Since we focus on a community as a static unit, we ultimately preclude change, it is essential to view communities as social creations. A community of practice is an aggregate of people who come together around some enterprise. United by this common enterprise, people come to develop and share ways of doing things, ways of talking, beliefs, values - in short, practices - as a function of their joint engagement in activity. Simultaneously, social relations form around the activities and activities form around relationships. Particular kinds of knowledge, expertise, and forms of participation become part of 'individuals' identities and places in the community." 
mente, em função dos seres que vivem em um meio concreto, em certas condições sociais, econômicas, estéticas, etc. (MATORÉ, 1953, p.43)

Assim, se tomamos o par termo-conceito, veremos que a atribuição de um conceito ao termo, ou a criação de um termo para expressar dado conceito, não se realiza somente por fatores internos da língua, "[...] eles são, no entanto, influenciados pelos contextos sociais e culturais que, muitas vezes, leva a diferentes categorizações" "' (ISO 1087-1, 2000, p.02). Não é nosso intuito, nesse momento, trabalhar com as construções conceptuais para os termos estupro/defloramento e como esses conceitos foram alterados ao longo do tempo. Como já expressamos anteriormente, nosso objetivo aqui é tão somente quantitativo ${ }^{10}$.

Sabendo que a linguagem de especialidade leva em conta os sujeitos, os contextos sociais e o momento temporal em que são produzidos os discursos, Faulstich (1998a) propõe um modelo de análise das variações terminológicas considerando que os itens do léxico especializado, como entidades históricas, devem ser analisados tanto no plano sincrônico quanto no diacrônico para que se possa ter dimensão total da evolução que o termo sofreu através dos tempos. Como sustentação às palavras da autora, Boulanger (1991, p.19) nos diz que "[...] a variação terminológica é necessária e é óbvio que a variação lexical ou linguística é vista em qualquer língua fragmentada no tempo, no espaço e na sociedade. Essas variações diacrônicas, diatópicas e diastráticas formam a essência da Socioterminologia ${ }^{11}$ ”. Ainda segundo Faulstich (1998a, p.03), “[...] nos percursos temporais da língua, o termo é uma entidade do discurso independentemente de sua realização no plano sincrônico e no plano diacrônico e, por isso, passível de

8 Tradução de Cambraia (2013). No original, “En réalité, les mots n'expriment pas les choses, mais la conscience que les hommes en ont. Pour la lexicologie, les faits sociaux ont en effet l'aspect de choses, mais ce sont des choses vues, senties, comprises par des hommes; notre discipline devra donc envisager les réalités sociologiques dont le vocabulaire est la "traduction" à la fois objectivement, comme des réalistés indépendantes de l'individu, et subjectivement, en fonction d'êtres vivant dans un milieu concret, dans certaines conditions sociales, économiques, esthétiques, etc."

9 Tradução nossa. No original, "They are, however, influenced by the social or culture background which often leads to different categorizations."

10 Obviamente, a matematização das frequências dos termos abre um caminho importante para a observação da mudança conceptual e, por conseguinte, semântica.

11 Tradução nossa. No original, "La variation terminologique est aussi nécessaire et evidente que la variation lexicale ou linguistique observée pour toute langue fragmentée dans le temps, dans l'espace et dans la société. Ces variations diachroniques, diatopiques et diastratiques forment l'essence même de la socioterminologie." 
apresentar variantes antigas e atuais". É com base nessas premissas de Faulstich que tomamos as variantes concorrentes ${ }^{12}$ estupro/defloramento.

\section{SOBRE 0 CORPUS E OS PROCEDIMENTOS METODOLÓGICOS}

Para este texto, tomamos um pequeno conjunto documental composto de três processos-crime de defloramento da cidade de Aracaju, que estão alocados no Centro de Documentação Histórica do Arquivo Geral do Poder Judiciário do Estado de Sergipe. As fontes remanescentes são todas manuscritas e estão datadas entre os anos de 1891 e 1894, a saber:

Quadro 1 - Informações estruturais de alocação do corpus

\begin{tabular}{|c|c|c|}
\hline ANO & COTA & OFENDIDA \\
\hline 1891 & $\begin{array}{c}\text { Cx 2544 } \\
\text { A1-M7-P11-01 }\end{array}$ & Idalina Cardoso Barretto \\
\hline 1893 & $\begin{array}{c}\text { Cx } 2544 \\
\text { A1-M7-P11-02 }\end{array}$ & Leopoldina Leite do Espírito Santo \\
\hline 1894 & $\begin{array}{c}\text { Cx } 2544 \\
\text { A1-M7-P11-04 }\end{array}$ & Alice Ramalho Porto \\
\hline
\end{tabular}

Fonte: Banco de dados do PHPB/SE

Para fins de preparação do corpus, todos os processos foram transcritos e, posteriormente, editados por meio do programa e-dictor. As edições semidiplomáticas seguiram as normas de edição do Projeto Para a História do Português Brasileiro (MARENGO; FREITAG, 2016).

Para obter máxima precisão e avaliar a frequência dos termos defloramento/estupro, optamos pelo uso da ferramenta computacional WordSmith Tools 7.0 (doravante WST). Nossos passos posteriores, a partir das edições geradas, consistiram em gerar listas de palavras por meio do WST: a) de cada processo completo individualmente; b) de cada processo, individualmente, por partes processuais codificadas; c) pelo conjunto de processos como um todo; e d) pelo conjunto de processos por partes processuais codificadas.

12 Variantes concorrentes são aquelas que podem concorrer entre si, ou que podem concorrer para um processo de mudança. São classificadas como variantes formais, isto é, são formas linguísticas ou exclusivas de registro que correspondem "[...] a uma das alternativas de denominação para um mesmo referente, podendo concorrer num contexto determinado" (FAULSTICH, 2002, p.77). 
Ao distribuir a amostra por esses quatro grupos, prosseguimos à análise da distribuição dos termos jurídicos estupro/defloramento dado o seu uso pelas três comunidades já mencionadas: a jurídica especializada (de juízes, promotores e advogados com voz nos processos), a intermediária (de escrivães, que apesar de terem contato contínuo com o "juridiquês" não possuem formação específica daquela comunidade de práticas), a não-especializada (das demais pessoas envolvidas no texto processual e que não possuem formação na área jurídica e nem estão em constante contato com a terminologia da lide jurídico-processual).

\section{ANÁLISE DOS DADOS}

Após a aplicação do tratamento terminométrico do corpus, chegamos aos resultados apresentados no gráfico 1. Verificamos que o defloramento (182) é muito mais incidente que o termo estupro (41) no início do Brasil República na cidade de Aracaju. Ao estendermos o tratamento mais geral a cada um dos processos que compõe o nosso estudo, observamos que não há assimetria em termos de usos. Em cada um dos processos, o termo defloramento possui maior frequência frente ao termo estupro.

Gráfico 1- Tratamento terminométrico geral dos termos defloramento/estupro

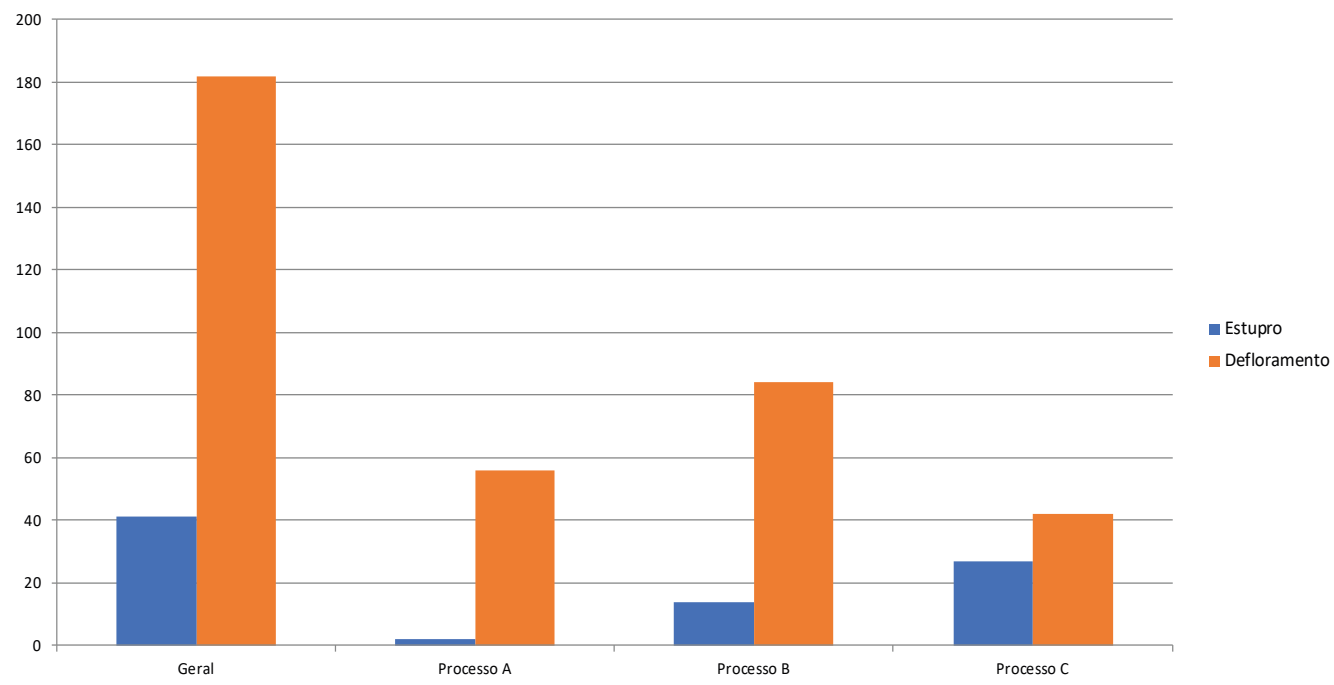

Fonte: Autoria própria 
Ao olharmos mais atentamente para o que nos revelam os dados do gráfico 1, veremos que a relação matemática entre os usos dos termos concorrentes estupro/defloramento vai aumentando ao longo do período estudado. No processo de 1891, a relação é de 0,035 (2/56); em 1893, é de 0,166 (14/84), e, por fim, em 1894, é de 0,642 (27/42).

Essa elevação da razão matemática está mais atrelada ao crescimento de uso do termo estupro. Verificamos, no gráfico 1, que as ocorrências do termo defloramento são relativamente equilibradas e estáveis ao longo do lapso temporal estudado. No entanto, o mesmo não se verifica com o termo estupro, que apresenta uma crescente em seu uso. Ao buscarmos uma possível justificativa para tal fenômeno, nos voltamos para os instrumentos jurídicos daquela época. A legislação penal vigente estava reunida no código Penal de 1890 que foi elaborado, segundo Hendz e Dornelles (2012), com o propósito de fazer a "construção da ordem legal republicana".

Nesse contexto, o fim da escravidão e o início do desenvolvimento urbano foram alguns dos fatores determinantes que justificaram a necessidade de publicação desse código pelos detentores do poder, no sentido de ter um conjunto de leis que regesse e determinasse as relações sociais de uma nova proposta de sociedade (HENDZ; DORNELLES, 2012, p. 300).

O código em questão traz uma seção em que estabelece, conceitua e penaliza os crimes contra a segurança da honra e honestidade das famílias e do ultraje público ao pudor. O crime de estupro faz parte dessa seção que apresenta em seus artigos,

Art. 267 - Deflorar mulher de menor idade, empregando sedução, engano ou fraude.

Art. 268. Estuprar mulher virgem ou não, mas honesta.

Art. 269. Chama-se estupro o ato pelo qual o homem abusa com violência de uma mulher, seja virgem ou não. Por violência entende-se não só o emprego da força física, como o de meios que privarem a mulher de suas faculdades psíquicas, e assim da possibilidade de resistir e defender-se, como seja o hipnotismo, o clorofórmio, o éter, e em geral os anestésicos e narcóticos. (BRASIL, CÓDIGO PENAL, 1980).

Comparado ao Código vigente no Brasil durante o período colonial e imperialista, o código de 1890, além de trazer o crime de estupro, também o define. $\mathrm{O}$ instrumento legal anterior a ele, apesar de apontar o crime de estupro, tinha 02 particularidades linguísticas que chamam atenção: (1) não trazia a definição precisa do crime e; (2) o verbo empregado ao acometimento do crime expresso por um substantivo era sempre deflorar. Como podemos verificar, o primeiro Código da República já porta o verbo estuprar. Chamamos atenção 
para esse fato, pois notamos que os verbos que apontam a ação do crime são os que, possivelmente, condicionam os seus usos terminológicos em diferentes esferas sociais. Por isso, durante todo o século XVIII (com a manutenção e aplicação jurídica por meio das Ordenações Filipinas), e, em XIX (perpassando pelo uso do Código Penal de 1830 até a publicação do de 1890), vemos um crime ser registrado como defloramento (derivado do verbo deflorar) e não estupro como nas leis vigentes. Isso ocorre na quase totalidade das fontes remanescentes dessa tipologia com as quais estamos trabalhando.

Assim, mesmo que a terminologia jurídica em sua natureza tenha um caráter normalizador e normatizador, os usos sociais em diferentes esferas de circulação e em distintas comunidades de práticas são mais fortes e impulsionadores do seu uso. Dessa feita, pensando nessa circulação e nas formas de possíveis difusões e encaixamentos dos termos e de seus conceitos específicos no seio social, é que acreditamos ser relevante quantificar esses usos terminológicos em comunidades de práticas que se expressem em semas como [+ jurídico], [-jurídico], [+poder] e [- poder]. Portanto, para observar o índice terminométrico das nossas amostras, dividimos nossos agentes em: (1) Especializados ([+ jurídico], [+poder]); (2) Semiespecializados ([+ jurídico], [-poder]); e (3) Não- especializados ([- jurídico], [- poder]). Os resultados obtidos podem ser observados no gráfico 2.

Gráfico 2 - Índice terminométrico de amostras por comunidades de práticas

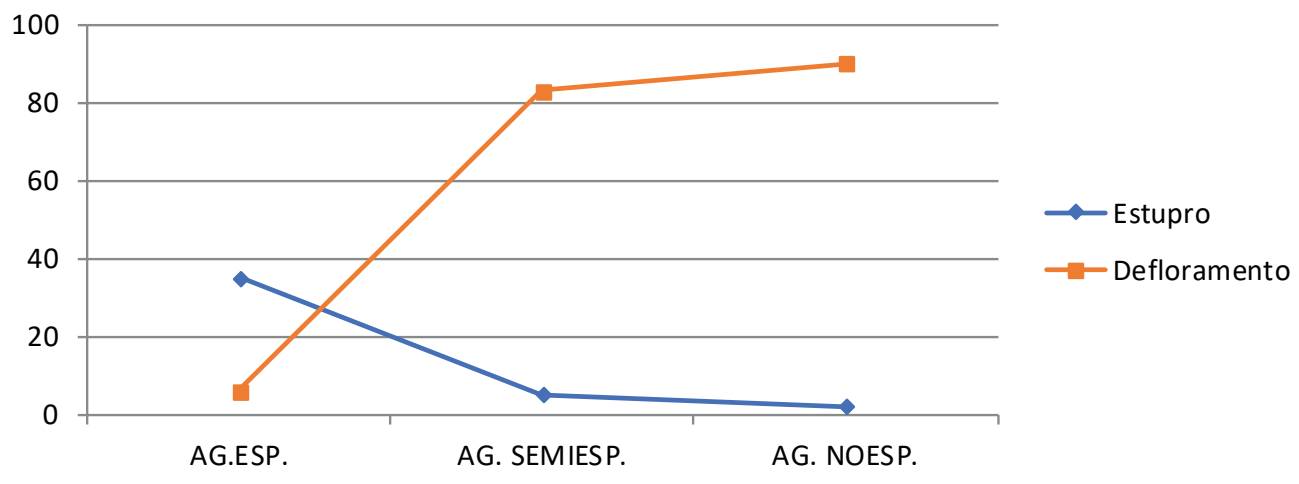

Fonte: Autoria própria

Ao observarmos os usos dos termos na nossa amostra, verificamos que os agentes especializados, com formação e instrução jurídica formal ${ }^{13}$, preferem

13 Obviamente, em estudos posteriores, teríamos que considerar que rábulas ocupassem a posição de agentes especializados, ainda que não tenham formação e instrução jurídica formal. 
quase totalmente a nomeação do crime dado pelo instrumento jurídico em vigor, ou seja, estupro (35/41). Assim, à luz da socioterminologia, a forma de maior ocorrência se alinha com o esperado de uso por sua comunidade de práticas. No outro extremo, é possível notar que os agentes não-especializados preferem quase totalmente o uso da forma mais difusa socialmente e não marcada terminologicamente como a designação do crime. De um universo de 90 ocorrências para uso de defloramento, houve somente 02 incidências para estupro. É curioso notar que as únicas duas aparições deste último termo por agentes não-especializados se deram em contexto de interação em que as perguntas realizadas eram:

\footnotetext{
Perguntado se sabia algo sobre o estupro na pessoa da offendida respondeu que nada sabia sobre o estupro. (PROCESSO B, 1893, fól. 27r)

Perguntado se tomou conhecimento da história do estupro commetido contra a offendida, respondeu que havia ouvido algo sobre isso, mas nada sabia sobre o estupro. (PROCESSO C, 1894, fól. 23v)
}

Os casos demonstrados possivelmente se explicam pela teoria da acomodação (GILES; COUPLAND, 1991), mas, como nosso intuito nesse estudo é somente quantitativo, não adentraremos nessa questão.

Por último, os usos feitos pelo agrupamento de agentes semiespecializados (escrivães) ficam em nível intermediário entre os dois já reportados. Esse lugar ocupado no meio de um fenômeno de variação nos dá indícios importantes sobre a figura dos escrivães e tabeliães na escrita da documentação jurídica de séculos pretéritos. Se tomarmos o que nos aponta o quantitativo terminométrico deste estudo, veremos que há um alinhamento maior com os usos não-especializados:

Obviamente que inferir a língua falada através da escrita num tipo de documentação oficial e relacionar questões lingüísticas e extralingüísticas requer talvez um tipo de metodologia própria. Entretanto, negligenciar indícios através de inferências de dados que possam ser significativos, ainda que relativamente escassos, é negligenciar talvez uma das possibilidades de se chegar a variedades históricas diversas do português brasileiro. Pelo menos, foi o que o contato inicial com a documentação oficial nos levou a pensar (CARNEIRO; ALMEIDA, 2002, p. 480-481)

É importante ressaltar que é esse grupo de agentes que faz, na maioria das vezes, a intermediação dos usos linguísticos por meio da escrita. São essas questões linguísticas e extralinguísticas advindas desse tipo de escrito, apontadas por Carneiro e Almeida (2002), que procuraremos desvendar. Por isso, acreditamos

No entanto, como não é o caso do corpus com o qual estamos trabalhando, isso não entrou em questão. Mas, é importante frisar que esses aspectos são importantes para que pensemos o conceito de comunidades de práticas em um viés diacrônico. 
que os índices terminométricos são de extrema importância para iniciar esse estudo. Os dados nos mostram que é justamente esse grupo intermediário que sustenta o fenômeno de variação léxico-semântico. Os demais agentes, como vimos, estão em posições praticamente categóricas nos usos de defloramento/ estupro. Como uma espécie de Hermes, mensageiro entre os deuses do Olimpo e os mortais da Terra, os agentes semiespecializados é que conduzem o fenômeno da variação. Essa assertiva nos leva a dois pontos importantes a serem pensados nos estudos terminológicos, principalmente aqueles de viés diacrônico:

(1) se os escrivães e notários representam a categoria entre os usos léxico-semânticos especializados e não-especializados, é possível, a partir de um estudo mais detalhado de sua escrita, mensurarmos o fluxo de um item lexical entre a linguagem geral e a de especialidade. Certamente, esse tipo de estudo nos levaria à compreensão mais acurada de variações e mudanças semânticas em âmbito terminológico;

(2) Cabré e Gómez de Enterría (2006, p. 21) entendem que a linguagem de especialidade é um "subconjunto de recursos específicos, linguísticos e não-linguísticos, discursivos e gramaticais que são usados em situações consideradas especializadas por suas condições comunicativas."'14

Sendo assim, os comportamentos linguísticos dos termos não poderiam ser diversos daqueles desempenhados pelos itens lexicais da linguagem comum e, portanto, alguns dos pressupostos já assentados na sociolinguística precisariam ser comprovados por meio de dados no rol da socioterminologia:

(a) A transição não-abrupta na linguagem geral no processo de mudança linguística (WEINREICH, LABOV, HERZOG, 1968) seguiria o mesmo padrão no âmbito especializado, afrontando, assim, o próprio caráter normatizador e impositivo da Terminologia clássica wüsteriana e das proposições da Lexicologia Social (MATORÉ, 1953);

(b) A hipótese curvilínea (LABOV, 2001) afirma que a mudança não tem suas origens nas classes sociais mais altas ou mais baixas, mas em grupos centralmente localizados na hierarquia socioeconômica. Logo, a mudança linguística que vem de baixo tem sua origem num grupo social central, localizado no interior de uma hierarquia socioeconômica (LABOV, 2001, p.188). Se essa é uma verdade já amplamente comprovada nos estudos

14 Tradução nossa. No original, "subconjuntos de recursos específicos, linguísticos y no linguísticos, discursivos y gramaticales que se utilizan en situaciones consideradas especializadas por sus condiciones comunicativas." 
sociolinguísticos para a linguagem geral, certamente a socioterminologia precisa investir em estudos que validem essa assertiva para as linguagens de especialidade.

Tanto (a) quanto (b) requerem um estudo mais detalhado da comunidade de práticas dos escrivães e tabeliães/notários. Como nossos dados iniciais demonstraram, a chave para o entendimento dos fenômenos de variação e mudança terminológicas está centrada na classe de agentes semiespecializados.

\section{CONSIDERAÇ̄EES FINAIS}

Trabalhar com textos de especialidade não é uma tarefa fácil, já que demanda que o linguista conheça bem os códigos da linguagem de especialidade. A Linguística Forense permite o diálogo profícuo entre as áreas de Letras e Direito, não só em sincronia presente como em passadas também. O conhecimento contextual da produção dos processos-crime nos permite, pelas sendas da História Social e Cultural, alcançar os modos de construção de ideias por meio da linguagem. No nosso caso específico de Sergipe oitocentista, tanto as ações comerciais e agrícolas quanto o deslocamento da capital acarretaram uma grande conurbação de pessoas oriundas de locais distintos. Esse amálgama humano e, por conseguinte, cultural criará um ambiente novo e propício para o aparecimento de conflitos que, pela letra da lei, serão mediados pela autoridade estatal, por meio da força policial, e pela jurídica. É esta última que nos interessa mais de perto, uma vez que os processos-crime de diferentes tipologias, além de serem fontes importantes para o desenho da história social e cultural do Sergipe no século XIX, também são importantes objetos para a (re)construção da situação linguística daquele momento.

O período cronológico que apontamos nesse estudo é bastante interessante devido à sua complexidade: em primeiro lugar, estamos recém-ingressos em um quadro político republicano e, posteriormente, do ponto de vista jurídico estamos trabalhando com um Código Penal de publicação bastante recente. Esses dois fatos, somados aos vários campos de exploração da história (econômica, social, cultural etc.), nos remetem a um ambiente bastante rico e favorável para entender como os usos e significados de estupro/defloramento se constroem e são construídos, significam e são significados em diferentes segmentos sociais em Aracaju de fins do século XIX.

A terminometria é um dos caminhos que podemos usar na tentativa de entender os usos léxico-semânticos e o caminho percorrido na trajetória da mudança 


\begin{abstract}
linguística. Concluindo, vimos que o trabalho da socioterminologia diacrônica dialoga com várias outras áreas de especialidade e isso nos leva a uma reflexão histórica e cultural que pode apontar tanto para as alterações do conceito atribuído a um termo quanto para sua criação lexical de um novo termo que expresse as variações conceituais (MARENGO, 2016). Além disso, esse movimento nos permite entender o meio sociocultural no qual circulam as linguagens de especialidades. Como bem nos afirma Kacprzak (2011), as análises diacrônicas em terminologia se assentam como importantes fontes de conhecimento sobre a maneira de como as gerações anteriores projetavam o mundo e, portanto, sobre a cultura partilhada em épocas passadas.
\end{abstract}

\title{
REFERÊNCIAS
}

ANJOS, Eliana Dantas dos. Glossário terminológico ilustrado de movimentos e golpes da capoeira: um estudo término-lingüístico. Dissertação (Mestrado em Filologia e Língua Portuguesa). São Paulo: FFLCH- USP, 2003.

BARROS, Lídia Almeida. Curso básico de terminologia. São Paulo: EdUSP, 2004.

BAUDET, Jean-Claude. Histoire du vocabulaire de spécialité, outil de travail pour l'historien des sciences et des techniques In: SCHAETZEN, Caroline de (Org.) Terminologie diachronique. Actes du coloque organisé à Bruxelles les 25 et 26 mars 1988. Bruxelles: Conseil international de la langue française/ Centre de Terminologie de Bruxelles/ Institut Libre Marie Haps, 1989.

BOULANGER, Jean-Claude. Une lecture sócio-culturelle de la terminologie. Cahiers de Linguistique Sociale, Terminologie et Sociolinguistique, 18. Université de Rouen/Mont-Saint-Aignan: GRECO-IRED, 1991. p. 13-30.

CABRÉ, María Teresa. La terminología: representación y comunicación - elementos para una teoría de base comunicativa y otros artículos. Barcelona: Institut Universitari de Linguistica Aplicada, Universitat Pompeu Fabra, 1999.

- La terminologia: teoría, metodología, aplicaciones. Barcelona: Editorial Antártida/Empúries, 1993.

CABRÉ, María Teresa; GOMEZ DE ENTERRÍA, Josefa. La enseñanza de los lenguajes de especialidad: la simulación global. Madrid: Gredos, 2006. 
CALDAS-COULTHARD, Carmen Rosa. ReVEL na Escola: O que é a Linguística Forense?. ReVEL, vol. 12, n. 23, 2014.

CAMBRAIA, César Nardelli. Da lexicologia social a uma lexicologia sócio-histórica: caminhos possíveis. Revista de Estudos Linguísticos, v. 21, n. 1, jan./jun. Belo Horizonte: Faculdade de Letras da UFMG, 2013. p. 157-188

CARNEIRO, Zenaide de Oliveira Novais.; ALMEIDA, Norma Lúcia Fernandes de. Notícias sobre o banco de textos de Feira de Santana e Cachoeira. In: ALKIMIN, Tânia Maria. (Org.). Para a história do português brasileiro. São Paulo: Humanitas/Fapesp, 2002, v. 3, p. 465-488.

ECKERT, Penelope. Linguistic variation as social practice. Oxford: Blackwell Publishing, 2004.

FAULSTICH, Enilde. Variação terminológica: algumas tendências no português do Brasil. In: Cicle de conferencies 96-97: lèxic, corpus i diccionaris. Barcelona: Universitat Pompeu Fabra, 1998.

. Entre a sincronia e a diacronia: variação terminológica no código e na língua. Conferência Magistral apresentada no VI simpósio da Rede Iberoamericana de Terminologia (RITERM). Havana, Cuba, 1998a.

- Aspectos de terminologia geral e terminologia variacionista. Revista do Centro Interdepartamental de Tradução e Terminologia. TRADTERM, nº 7. SP: Humanitas/FFLCH/USP, 2001. p. 11-40.

- Variação em terminologia. Aspectos de socioterminologia In: RAMOS, Gloria Guerrero; PÉREZ LAGOS, Manuel Fernando.(coord.). Panorama Actual de la Terminología. Granada: Editorial Comares, 2002. p.65-91.

GILES, Howard.; COUPLAND, Nicolas. Language: contexts and consequences. Pacific Grove (Ca): Brooks, Cole, 1991. 
HANSE, Joseph. Allocutions d'ouverture In: SCHAETZEN, Ca roline de (Org.) Terminologie Diachronique. Actes du coloque organisé à Bruxelles les 25 et 26 mars 1988. Bruxelles: Conseil international de la langue française/ Centre de Terminologie de Bruxelles/ Institut Libre Marie Haps, 1989.

HENDZ, Aquéle.; DORNELLES, Jônatas Herrmann. O Código Penal de 1890 e a construção das relações de gênero, no julgamento dos processos-crime de homicídios, entre 1900 e 1940, na Comarca Caxias. MÉTIS: história \& cultura v. 11, n. 21, p. 297-314, jan./jun. 2012. p.297-314.

ISO 1087-1 (E/F). Terminology work - Vocabulary, Part 1: theory and application / Travaux terminologiques - Vocabulaire - Partie 1: théorie et application. Genève: International Standard Organization, 2000.

KLEIBER, Georges. Problèmes de sémantique: la polysémie en questions. Lille: Ed. du Septentrion, 1999.

KOCOUREK, Rostislav. La langue française de la technique et de la science, vers une linguistique de la langue savante. Wiesbaden: Brandstetter Verlag $\mathrm{GMbH}$ und Co. KG, 1991.

KRIEGER, Maria da Graça; FINATTO, Maria José Bocorny. Introdução à terminologia: teoria e prática. São Paulo: Contexto, 2004.

LABOV, William. Principles of linguistic change: social factors. Oxford: Blackwell, 2001.

MARENGO, Sandro Marcío Drumond Alves. Variações terminológicas e diacronia: estudo léxico-social de documentos militares manuscritos dos séculos XVIII e XIX. 2016. Tese (Doutorado em Estudos Linguísticos) - Faculdade de Letras, Universidade Federal de Minas Gerais, 2016.

- Crítica textual e linguística histórica em manuscritos militares. Revista da Associação Brasileira de Linguística (ABRALIN), Paraná, UFPR. n.16 (3), 2017. p.245-264. 
. Mudança linguística à luz da socioterminologia diacrônica: a história da cultura escrita como fator extralinguístico. REVEC-Revista de Estudos de Cultura, v. 3, 2018a. p. 59-76.

. Instruções militares que contém os princípios geraes de tactica (FBN-I-14, 01, 039): edição semidiplomática e glossário terminológico. In: XIMENES, Expedito Eloísio.; NUNES, Ticiane Rodrigues (orgs). Estudos filológicos e linguísticos na Bahia, no Ceará e em Sergipe. Fortaleza: EdUECE, 2018 b.

MARENGO, Sandro Marcío Drumond Alves; CAMBRAIA, César Nardelli. Estudo socioterminológico da variação/mudança em manuscritos militares os séculos XVIII e XIX. Revista Interdisciplinar, São Cristóvão, Sergipe, Ano XI, v. 24 jan./abr, 2016. p.203-224.

MARENGO, Sandro Marcío Drumond Alves; FREITAG, Raquel Meister Ko. Para uma história do português brasileiro em Sergipe: organizando as fontes manuscritas e suas edições. Revista do Instituto Histórico e Geográfico de Sergipe, Aracaju, v. 1, n. 46, 2016. p.116-129.

MATORÉ, Georges. La méthode en lexicologie. Domaine Français. Paris: Libraire Marcel Didier, 1953.

SIMÕES, José da Silva; KEWITZ, Verena. Recortes temáticos e mapeamento de tradições discursivas no corpus do PHPB In: HORA, Dermeval da; SILVA, Camilo Rosa da (orgs.). Para a História do Português Brasileiro: abordagens e perspectivas. João Pessoa: Ideia/Editora da UFPB, v. VIII, 2010. p.21-28.

SOUZA, Ivan Pereira de. Do engenho à usina: estudo diacrônico da terminologia do açúcar. Dissertação (Mestrado em Filologia e Língua Portuguesa). São Paulo: FFLCH- USP, 2007.

WEINREICH, Weinreich; LABOV, William; HERZOG, Marvin. Empirical foundations for theory of language change. In: LEHMANN, Paul; MALKIEL, Yakov. (eds.) Directions for historical linguistics. Austin: University of Texas Press, 1968. p.95-188. 
